\title{
Comparison of conventionally and naturally coloured coatings marked by laser technology for unique 2D coding of pharmaceuticals
} \author{
Géza Regdon jr ${ }^{\mathrm{a}, \mathrm{H}}$ \\ a Institute of Pharmaceutical Technology and Regulatory Affairs, University of Szeged, Eötvös utca 6, 6720 Szeged, Hungary \\ ${ }^{\mathrm{b}}$ MTA-SZTE Research Group on Photoacoustic Spectroscopy, University of Szeged, Dóm tér 9, 6720 Szeged, Hungary \\ ${ }^{c}$ Department of Optics and Quantum Electronics, University of Szeged, Dóm tér 9, 6720 Szeged, Hungary
}

Krisztina Ludasi ${ }^{\mathrm{a}}$, Orsolya Jójárt-Laczkovich ${ }^{\mathrm{a}}$, Tamás Sovány ${ }^{\mathrm{a}}$, Béla Hopp ${ }^{\mathrm{c}}$, Tomi Smausz ${ }^{\mathrm{b}, \mathrm{c}}$

\section{A R T I C L E I N F O}

\section{Keywords:}

Personalised medicines

Falsified medicines

Identification

Anti-counterfeiting

Laser marking

Unique laser coding

Naturally coloured coating

\begin{abstract}
A B S T R A C T
Substandard and/or falsified medicines are a growing global threat for health and they cause serious social and economic damage. In low- and middle-income countries the failure rate of these medical products is approximately $10.5 \%$. $50 \%$ of medicines purchased over the Internet may be fake.

According to Directive 2011/62/EU as regards the prevention of falsified medicines from entering into the legal supply chain, a unique identification should be put on each box of drugs in the EU from 9th February 2019.

The current project is focusing on the development of a laser technology to mark an individual traceable code on the surface of the tablet. Usually, coatings contain titanium dioxide for sufficient coverage, which makes precision laser coding more difficult. New naturally coloured films do not include those excipients. In this research, we would like to compare the physical-chemical properties of conventionally and naturally coloured coatings after the laser marking procedure by using two types of lasers.

This unique identification technology can be used for marking personalized medicine with the doses tailored for each patient, too.

To sum up, the present findings may contribute to efficient and reliable laser marking solutions in the unique identification procedure. Based on our measurement results, it can be stated that excimer UV lasers are promising candidates as marking instruments for the polymer film in both conventionally and naturally coloured coatings.
\end{abstract}

\section{Introduction}

Substandard and falsified (SF) medicinal products are a growing problem, as they damage patients' health, the society and the economy. The World Health Organization, (WHO) adopted the name SF for the medical products that fail to meet either national or international quality standards or specifications at its 70th World Health Assembly in 2017 (WHO, 2017a; World Health Assembly, 2017).

According to the reports from WHO (2017), in low- and middleincome countries the failure rate of SF medical products is approximately $10.5 \%$ (WHO, 2017b, 2017c), which means that due to SF medicines each year 72,000 to 169,000 children may die of pneumonia, or $64,000-158,000$ additional deaths of malaria could be caused according to the estimations of the University of Edinburgh and London School of Hygiene and Tropical Medicine, respectively (WHO, 2017d). In 2013 an estimated 122,350 (IQR: 91,577-154,736) under-five deaths were associated with the consumption of poor-quality antimalarials only in 39 sub-Saharan African countries, which suggests that these poor-quality medicines are important contributors to child mortality (Renschler et al., 2015) and may help the spread of growing resistance geographically. The number of drugs is also growing in the global marketplace, especially sales on the Internet (Nayyar et al., 2019), which has become an accepted, and more and more popular way to purchase medications in high-income countries since the establishment of the first Internet pharmacies (Gallagher and Colaizzi, 2000; Ghinea et al., 2006). Unfortunately, by now about $50 \%$ of medicines purchased over the Internet are falsified because of the increase of illegal activities (UNICRI, 2012; WHO IMPACT, 2006; Wilczyński, 2015), as they can easily circumvent regulatory oversight (Siva, 2010), and globalization makes it harder to regulate the medical products that are sold in this way (Bichell, 2017).

Most of the counterfeiters produce and print packaging in different

\footnotetext{
* Corresponding author at: University of Szeged, Institute of Pharmaceutical Technology and Regulatory Affairs, H-6720 Szeged, Eötvös u. 6, Hungary

E-mail address: geza.regdon@pharm.u-szeged.hu (G. Regdon).
} 
countries, shipping components to the final destination, where they are assembled and distributed (WHO, 2017d). Parallel imports also pose a significant risk to the safety of patients, especially when the product has to be repackaged, which is generally not allowed, but sometimes it is objectively necessary, e.g., to suit the target country's national language (European Commission, 2003; Said et al., 2011). Nevertheless, the removal of blister packs from their original external packaging and their insertion with one or more original packages into new external packaging, or their insertion into another original package, the insertion of new user instructions in national languages, or the fixing of selfstick labels on original external packaging or blister packs is considered as an activity which shall not affect the condition of the medicinal product inside the packaging. The necessity of repackaging must be justified by the parallel distributor in the course of a notification procedure (European Medicines Agency, 2019).

Managing illicit drug trafficking and limiting access to potentially counterfeit medicines should be a priority for governments and drug delivery systems (Vida et al., 2017). Recently, global pharmaceutical supply chains have been developing stricter regulatory requirements. In the USA, the FDA's Drug Supply Chain Security Act sets out the necessary steps to implement an electronic, interoperable system to identify and trace prescription drugs distributed in the US (FDA, 2014).

To prevent falsified medicines from entering the legal supply chain, the European Union adopted Directive 2011/62/EU (European Commission Staff Working Document, 2015; The European Parlament and the Council of the European Union, 2011). The EU Commission gave additional technical details for the further design of security features with the Delegated Regulation (EU) 2016/161. From 9th February 2019 serialization, traceability and verification for prescription-only medicines are obligatory requirements in the EU. This requires a new safety feature, a unique 2D data matrix barcode, which should be put on each box of drugs (European Comission, 2016).

To protect medical products, a large number of security technologies can be used for authentication. The choice of technology depends on the available financial resources, security level, feasibility, etc. It is recommended to use more than one technology at the same time to provide an effective protection against counterfeiting. The technologies that can be used include, but are not limited to the following: Printing technologies (offset lithography, flexography, gravure, screen printing, laser printing, pad printing, embossing and debossing, laser engraving, inkjet printing), security labels (adhesive, frangible, security cuts and perforation, void labels, holograms) and/or tracking technologies (serial numbers, linear bar codes, matrix codes, radio frequency identification (RFID)) may be used on the packaging of the medicines(Davison, 2011). Furthermore, various methods such as unique coating colours, shapes, tooling, texture, sizes, physical feature, unique tablet designs, logos, texts, pearlescent film, printing etc. may be used for on-dose visual identification, while physical-chemical identifiers (PCIDs) include inks, pigments, flavours, and molecular taggants. For example, TruTag's on-dose authentication (TruTag Technologies, 2019), Microtag (Nogaja, 2013), may be incorporated into solid oral dosage forms as in-dose features. Some PCIDs could require the use of instrumental detection.

The final aim of the present project is to extend the regulation provided by the Directive and to develop a technology for marking individual traceable 2D codes directly on the surface of the tablet. With this process, it would be easier to provide tablet authentication and to avoid illegal repackaging. As most existing anti-counterfeit technologies are on the drug packaging, it is easy for unscrupulous traders to exchange quality drugs (You et al., 2016). The QR code on the surface of the tablet is an excellent opportunity because of its high-capacity and error-correctability, its comprehensive reading ability, and its rapid and easy generation (Fei and Liu, 2016).

Besides anti-falsification, this unique identification technology is also suitable to label personalized medicines with codes tailored for each patient on each tablet. This information is increasingly needed for older persons following a prolonged complex drug regimen as they make mistakes when taking their medication (Mira et al., 2015), or when dose flexibility is needed for specific patient groups depending on age, gender, weight and genetic background (Edinger et al., 2018; Vakili et al., 2015). Coding could have benefits in terms of remote monitoring like tracking of medicine, or medicine reminder and monitoring system (Zanjal and Talmale, 2016). Furthermore, in hospitals, it is important to have a method to keep track of individual medicines dispensed to patients to avoid severe health risks. When the medicine leaves its packaging, it becomes impossible to identify the drug unless the leaflet remains accessible. The problem is the lack of information on the medicine itself (Kato et al., 2010).

Other research groups are also investigating alternative techniques for the direct marking of dosage forms. You et al., applied a fluorescent 3D QR code consisting of three different colour layers directly printed on the surface of the drug capsules. By using the multilayer printing and splitting technology, where each layer encodes information of different aspects of the drug and may be decoded by a specific smartphone application, the information storage capacity per unit area increases (You et al., 2016). Another study reports the interface between 3D printing and $2 \mathrm{D}$ inkjet printing technologies in order to fabricate a drug-loaded 3D printed tablet with a unique track-and-trace measure in a single step process. 2D codes were printed onto the surface of polymeric based printlets for scanning using a smartphone device and were designed to encode tailored information pertaining to the drug product, patient and prescriber. Plus, a novel anti-counterfeit strategy was designed, which involved the deposition of a unique combination of material inks for detection using Raman spectroscopy (Trenfield et al., 2019). In a third case, $\mathrm{CO} 2$ laser engraving was used to achieve roughness over different surfaces causing a difference in the grey levels on tranFslucent materials. This effect and the micro mold process was used to achieve micro pattern of the QR code and to obtain drug-laden biodegradable label (Fei and Liu, 2016).

In the present study laser ablation has been chosen for marking because it overcomes the drawbacks of the most popular printing methods (like offset-, ink-jet-, and pad printing), where the clear printing pattern may easily be affected by the environmental conditions of the process room, uniformity, temperature, and drying of the ink (Hosokawa and Kato, 2011). Printability is also affected by ink viscosity and surface tension, the size of the nozzle (Daehwan et al., 2009), the surface roughness of tablets, which may cause problems such as mottled appearance, blur, or dirt of the inks (Kato et al., 2010). Most of the ink printing requires contact between the substrate and some form of ink carrier, toner reservoir, or stamp so that could be a source of contamination (Davison, 2011). In addition, organic solvents which are harmful to the employees' health and the environment are often used for the inks (Kato et al., 2010). In contrast, laser ablation is a noncontact method that avoids the problems of the above-mentioned ink printing technologies and eliminates the cost of consumables using ink.

The final plan is to put two coatings on the tablet surface in different colours, a functional one and a second one for marking. After the laser ablation of the upper film layer, the differently coloured code could be read even by the patient using a mobile phone with the appropriate application. In the literature, there are several studies on mobile phones as a device capturing image and processing data for the authentication of fake drugs (Edinger et al., 2018; Fei and Liu, 2016; Karen Langhauser, 2013; Mackey and Nayyar, 2017; Ur Rehman et al., 2011). This coding process could have benefits for tracking drugs across the distribution chain and for adding information for personalised medicines. However, the 2D code on the surface of the medicine could have an impact on the visual appearance and affect the acceptance of medication by patients (Trenfield et al., 2019).

Preliminary studies (Ludasi et al., 2018) have shown that the use of conventional coatings, containing titanium dioxide and talc to achieve better surface coverage, could make precision laser coding more difficult. Therefore, as a response to the growing demand for natural 
materials, and since new naturally coloured film formulations do not include the excipients mentioned above, the current research is focusing on the comparison of the physical-chemical properties of conventionally and naturally coloured coatings after the laser marking procedure by two different types of lasers.

The selection criteria for lasers were the comparison of completely different types of instruments to provide a broader overview of the effects of different lasers. The pulsed mode excimer laser works with photochemical ablation, which seems to have a more gentle effect on the structure of the coating. However, it uses gas mixtures, usually noble gas and halides, and the running costs are high due to the maintenance and equipment costs (E. Kannatey-Asibu Jr., 2009; Steen and Mazumder, 2010). In contrast, the continuous mode semiconductor (diode) laser ablates by the photothermal effect and has the advantages of being compact, efficient, with a quick modulation response and reliability. It is relatively small in size and easy to fabricate by mass production, thereby it has a low cost. In addition, they operate at different wavelengths.

\section{Materials}

\subsection{Coating materials}

HPMC based ready-to-use coating formulas: Sepifilm PW Red, PW Green, PW White and naturally coloured Sepifilm NAT Pink and NAT Green (Seppic S.A., Paris La Defense, France) were used dispersed in distilled water.

\section{Methods}

\subsection{The plastic ball coating procedure}

In this study, experiments were done on coating films, sprayed on the surface of polyethylene balls (Primary Balls Kft., Budaörs, Hungary) with an outer diameter of $2.5 \mathrm{~cm}$ under the same conditions as previously used on tablets. Thereafter the film was removed from the ball, marked by laser and examined.

The aqueous HPMC coating solutions consisting of 15\% w/w dry substance in the case of SEPIFILM ${ }^{\mathrm{TM}}$ NATurally COLoured coatings agents, and $20 \% \mathrm{w} / \mathrm{w}$ dry substance in the case of Sepifilm ${ }^{\mathrm{TM}}$ PW coating systems, according to the supplier's recommendation, were prepared by dispersing them in distilled water. The total mixing time lasted for $45 \mathrm{~min}$, followed by passing the dispersion through a $0.5 \mathrm{~mm}$ sieve.

4 M8 Pancoat (ProCepT, Zelzate, Belgium) perforated coating pan was used for spray coating. 35 pieces of balls were coated at the same time in four stages. The coating parameters are shown in Table 1. A $0.8 \mathrm{~mm}$ spray nozzle was used for the application of the atomised spray coating solution for $55 \mathrm{~min}$, with an atomising air pressure of 2.0 bars and an air flow rate of $0.70 \mathrm{~m}^{3} / \mathrm{min}$. The drying and cooling process lasted for $15 \mathrm{~min}$ each.

\subsection{Irradiation of coating films with 2 types of laser}

In the first step the coating films were irradiated with a LLG TWINAMP type ArF excimer laser (wavelength: $193 \mathrm{~nm}$, energy:

Table 1

The coating parameters of balls.

\begin{tabular}{lllll}
\hline Step & $\begin{array}{l}\text { Inlet air } \\
\text { temperature }\left({ }^{\circ} \mathrm{C}\right)\end{array}$ & $\begin{array}{l}\text { Exhaust air } \\
\text { temperature }\left({ }^{\circ} \mathrm{C}\right)\end{array}$ & $\begin{array}{l}\text { Ball temperature } \\
\left({ }^{\circ} \mathrm{C}\right)\end{array}$ & $\begin{array}{l}\text { Drum } \\
\text { speed } \\
(\mathrm{rpm})\end{array}$ \\
\hline Warm-up & 60 & N/A & Until 50 & 3 \\
Coating & $50-55$ & $40-42$ & 45 & 9 \\
Drying & 40 & 30 & 27 & 3 \\
Cooling & 25 & 25 & 25 & 3 \\
\hline
\end{tabular}

$3 \pm 0.2 \mathrm{~mJ}$, fluence: $444 \mathrm{~mJ} / \mathrm{cm} 2$, FWHM: $20 \mathrm{~ns}$, spot size: $375 \mu \mathrm{m}$ ), using a simple square-shaped mask, which has resulted in a $1 \mathrm{~mm}^{2}$ square-shaped ablation hole, to study the effect of the laser on the coating film. The extension of the ablation procedure to achive the planned 2D imaging requires the combination of the laser with a precise CNC stage.

The effect of a CW semiconductor laser (wavelength: $405 \mathrm{~nm}$, spot size: $73 \mu \mathrm{m}$, power: $1000 \mathrm{~mW}$, irradiation time: $15-20 \mathrm{~ms}$ ) on the quality of the coating films was also tested. In this case a full QR code was generated using online ZXing ("Zebra Crossing") code generator software, an open-source, multi-format 1D/2D barcode image processing and code generator library implemented in Java. The standard QR code was generated (ISO/IEC 18004:2015) with 8 numerical characters using 300 dpi resolution and lowest error correction (Level L). For reading the $\mathrm{QR}$ code, the same software application was used by a mobile phone. The 3D geometric correction has not yet been applied to the $2 \mathrm{D}$ images, since it was projected to the coating film, which has a negligible curvature compared to the real tablet surface.

\subsection{Digital microscope}

The surface morphology of the ablated film was observed by using a Digital Microscope (KEYENCE, VHX-6000). This instrument is equipped with a newly developed REMAX VI High-Performance Graphics Engine and D.F.D. 2.0 image processing engine. This enables the creation of a precise 3D image by analysing small changes in texture after capturing numerous images at different heights and different angle positions, HDR and image-stitching. Through line roughness and surface roughness measurements, reliable evaluation of surfaces can be performed and converted to a figure.

Data was evaluated by HDR playback / measurement / stitched image playback software developed by KEYENCE.

\subsection{Surface profilometer}

Profilometry measurements were performed on a Veeco, Dektak 8 Advanced Development Profiler ${ }^{\oplus}$. The tips employed had a radius of curvature $\sim 2.5 \mu \mathrm{m}$, and the force applied to the surface during scanning was $\sim 30 \mu \mathrm{N}$. The horizontal resolution was $0.1-0.13 \mu \mathrm{m}$. The vertical resolution was $40 \AA$ A. Data was evaluated by Dektak software (Microsoft ${ }^{\circledR}$ Windows XP ${ }^{\circledR}$ : interactive data acquisition) and Vision ${ }^{\circledR} 32$ software (data processing, 2-D and 3-D image analysis) (Veeco Instruments Inc., New York, USA)

\subsection{Raman spectra}

Films treated by a laser were investigated by Raman spectroscopy. Spectra were acquired with a Thermo Fisher DXR Dispersive Raman (Thermo Fisher Scientific Inc., Waltham, MA, USA) equipped with a CCD camera and a diode laser operating at a wavelength of $780 \mathrm{~nm}$. Raman measurements were carried out with a laser power of 12 and 24 $\mathrm{mW}$ at $25 \mu \mathrm{m}$ slit aperture size. Spectra of the individual films and films treated by two different lasers were collected using an exposure time of $6 \mathrm{sec}$. The data were collected in the spectral range of $3407-24 \mathrm{~cm}^{-1}$ using automated fluorescence corrections. OMNIC 8 software was used for data collection, averaging the total of 20 scans and making the spectral corrections. For the removal of cosmic rays, a convolution filter was applied to the original spectrum using Gaussian kernel.

\subsection{Thermal gravimetric analysis (TGA)}

The thermal gravimetric analysis of the samples was carried out with a Mettler-Toledo TGA/DSC1 instrument (Mettler-Toledo GmbH, Switzerland). The start temperature was $25^{\circ} \mathrm{C}$, the end temperature was $500{ }^{\circ} \mathrm{C}$, the applied heating rate was $10^{\circ} \mathrm{C} / \mathrm{min}$. Nitrogen atmosphere was used (cell gas: $50 \mathrm{ml} / \mathrm{min}$, method gas: $70 \mathrm{ml} / \mathrm{min}$ ). $5 \pm 1 \mathrm{mg}$ of 


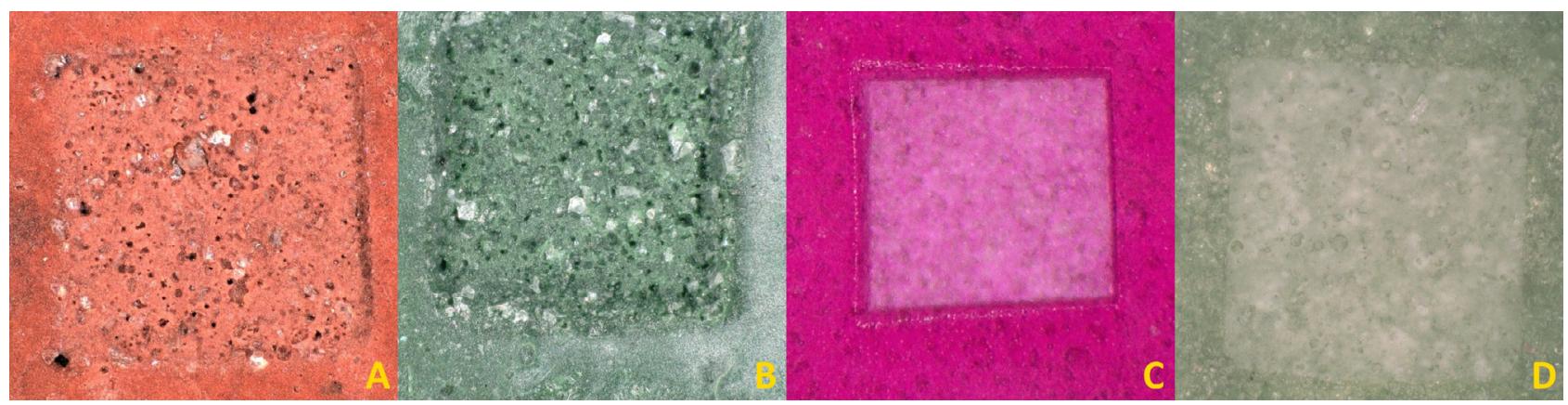

Fig. 1. Coating films treated by excimer laser: Sepifilm PW Red (A), PW Green (B), Sepifilm Naturally Coloured Pink (C) and Green (D).

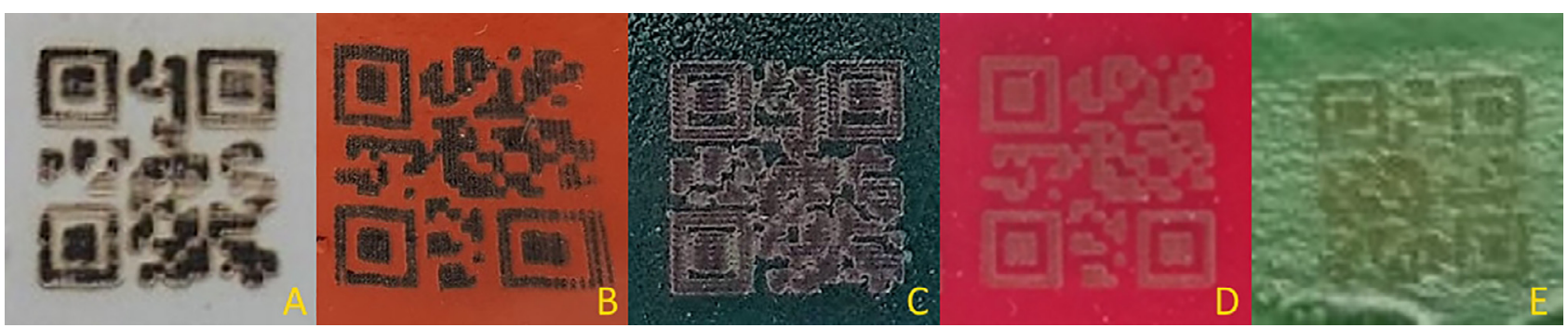

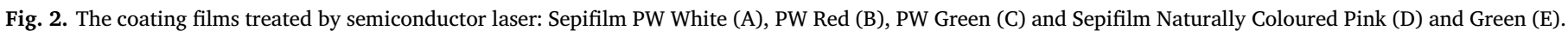

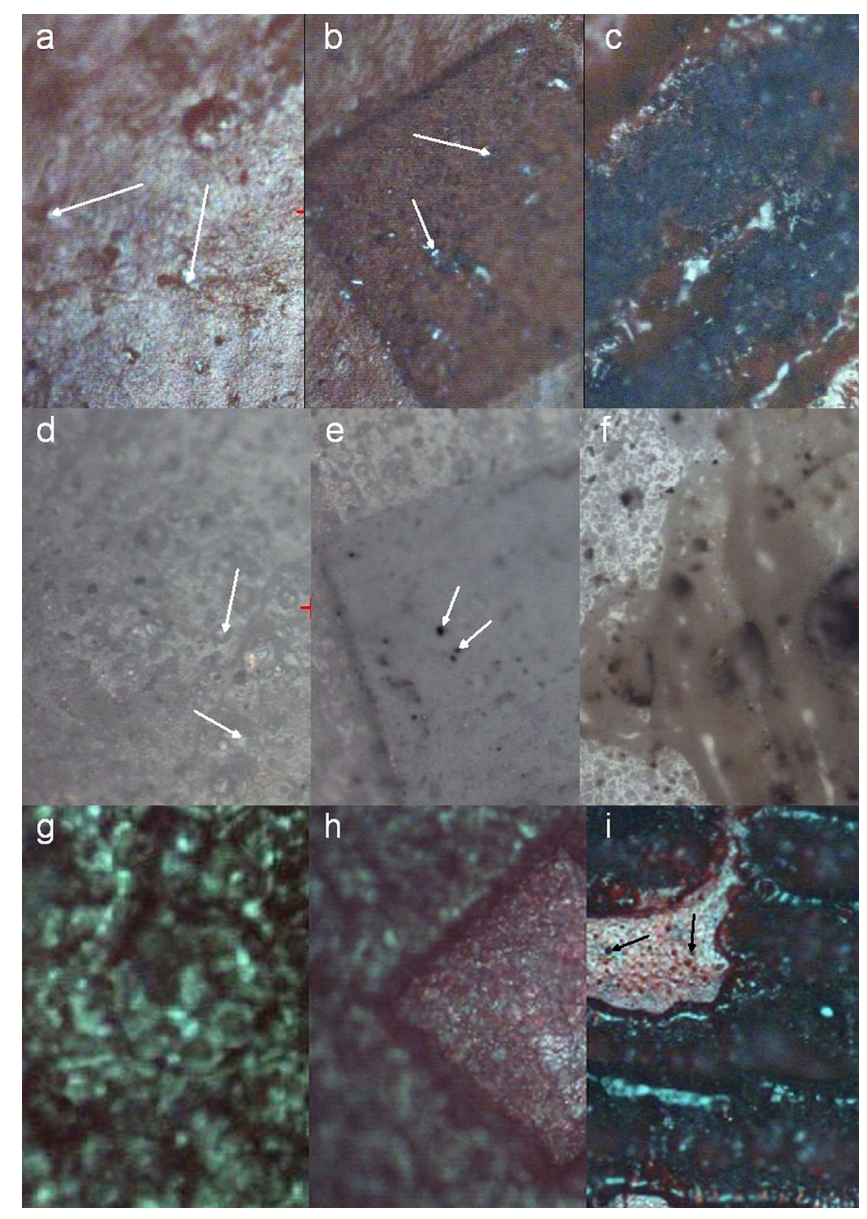

Fig. 3. Microscopic picture of untreated films (first column: a, d, g), films treated by excimer laser (second column: b, e, h) and films treated by semiconductor laser (third column: c, f, i). Sepifilm PW Red (a, b, c), PW White (d, e, f), and Sepifilm Naturally Coloured Pink (g, h, i). samples were measured into aluminium pans $(40 \mu \mathrm{l})$. The peak areas were evaluated with Mettler-Toledo STARe Software.

\section{Results and discussion}

The present study is focusing on the comparison of conventionally coloured and naturally coloured coatings that are talc- and titanium dioxide-free, to clarify how the titanium dioxide particles interfere with laser ablation. Films were sprayed on the surface of polyethylene balls, removed and marked with 2 different types of lasers. After marking the polymer films, a detailed quality analysis was made to check if there occurred any change during the laser intervention in different films.

\subsection{Surface}

Laser marked films were examined first by a 3D digital microscope. The investigated lasers had different effects on the films. The excimer laser's material removal mechanism is photochemical ablation. The energy of the ultraviolet photon is between 3.5 and $6.5 \mathrm{eV}$, which is similar to the molecular bonding energy for many organic materials (the energy associated with the $\mathrm{C}-\mathrm{C}$ bond is roughly $4.6 \mathrm{eV}$, while that of the $\mathrm{C}-\mathrm{H}$ bond is about $4.2 \mathrm{eV}$ and $6.42 \mathrm{eV}$ in our case). When an organic material is irradiated with an ultraviolet beam, the compounds efficiently absorb the beam's energy in a very thin layer of the order of submicron, near the surface. This breaks molecular bonds, causing ablative decomposition of the irradiated area. The process occurs almost instantaneously, there is no time for any heat transfer. The resulting edges are well defined, with minimal thermal damage to the surrounding area, which is why the process is also called cold ablation.

In contrast, semiconductor lasers ablate material by a photothermal effect. Heat flows by thermal conduction and material evaporates by boiling after prior melting or burning. However, this thermal heating may cause material removal by routes other than straight boiling. By the sufficient heating of the material, the vibrations can break the weaker bonds, and the boiling point of the broken structure may be lower than that of the original structure and evaporation occurs without the reaching of the melting point, which is of particular relevance to polymers (Kannatey-Asibu Jr., 2009; Steen and Mazumder, 2010).

The effects of the different lasers on the ablated polymer films are 


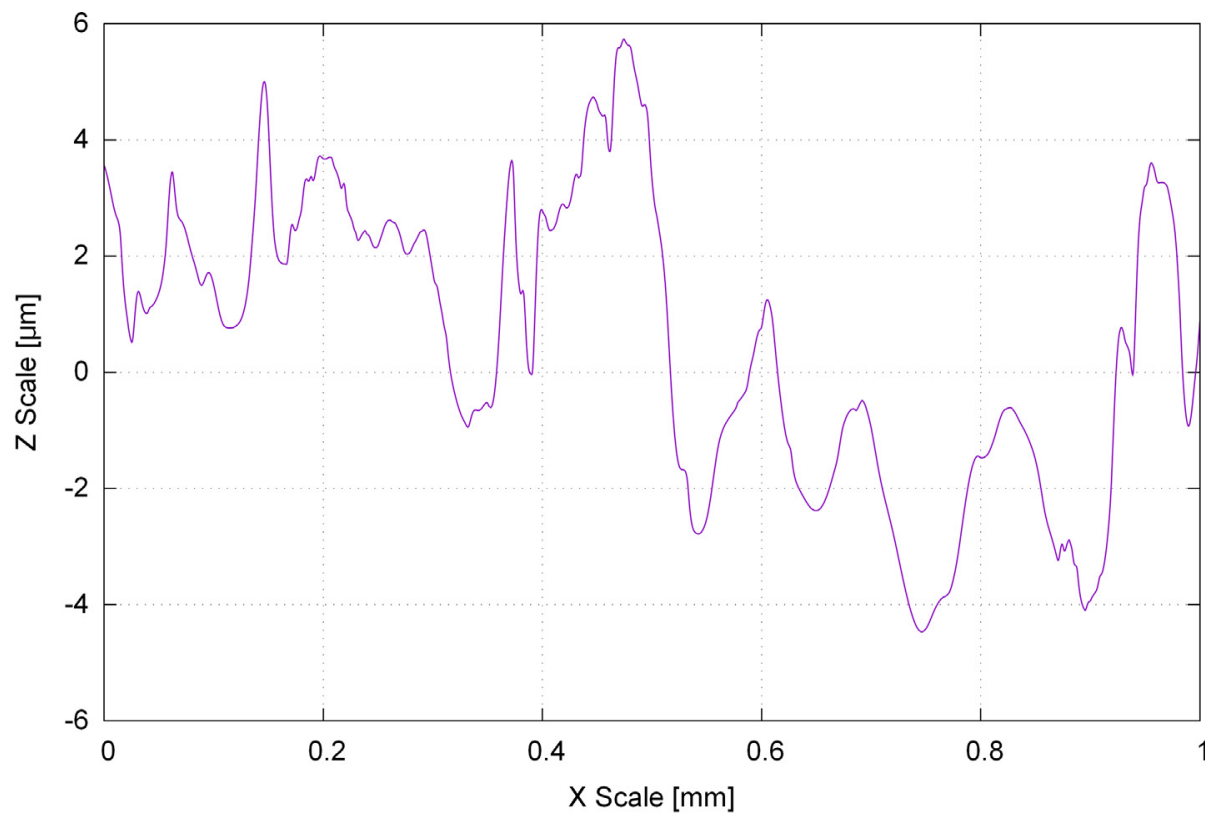

Fig. 4. Typical untreated tablet surface roughness measured with profilometer.
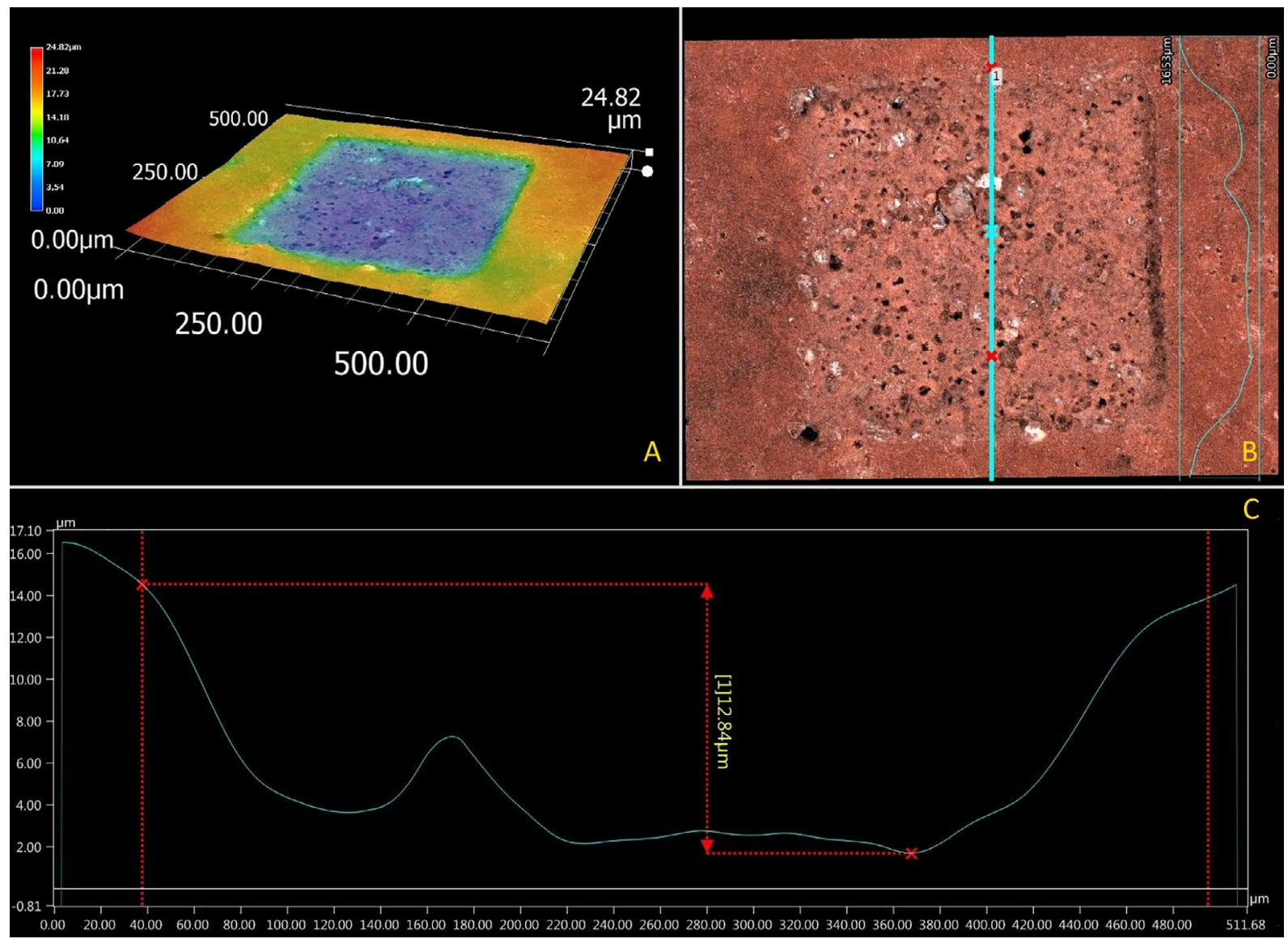

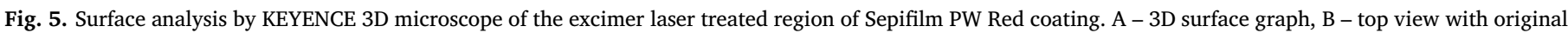
colours of the ablation hole, $\mathrm{C}$ - profile analysis. The white titanium dioxide particle is marked with a yellow circle.

seen in Figs. 1 and 2, showing the holes ablated by the excimer laser, and the markings achieved by the semiconductor laser, repectively. During the excimer laser ablation, the square-shaped holes on the film returned the shape of the mask used. The ablations of the differently coloured coatings were considerably different: coatings PW Red and PW
Green, containing titanium dioxide and talc, are seen in Fig. $1 \mathrm{~A}$ and B, where white and black particles are visible. The is no similar phenomenon on the laser treated surface of the naturally coloured NAT Pink and NAT Green coatings (Fig. 1C and D). The resulted shape is much sharper, and the surface is much smoother in this type of coating 


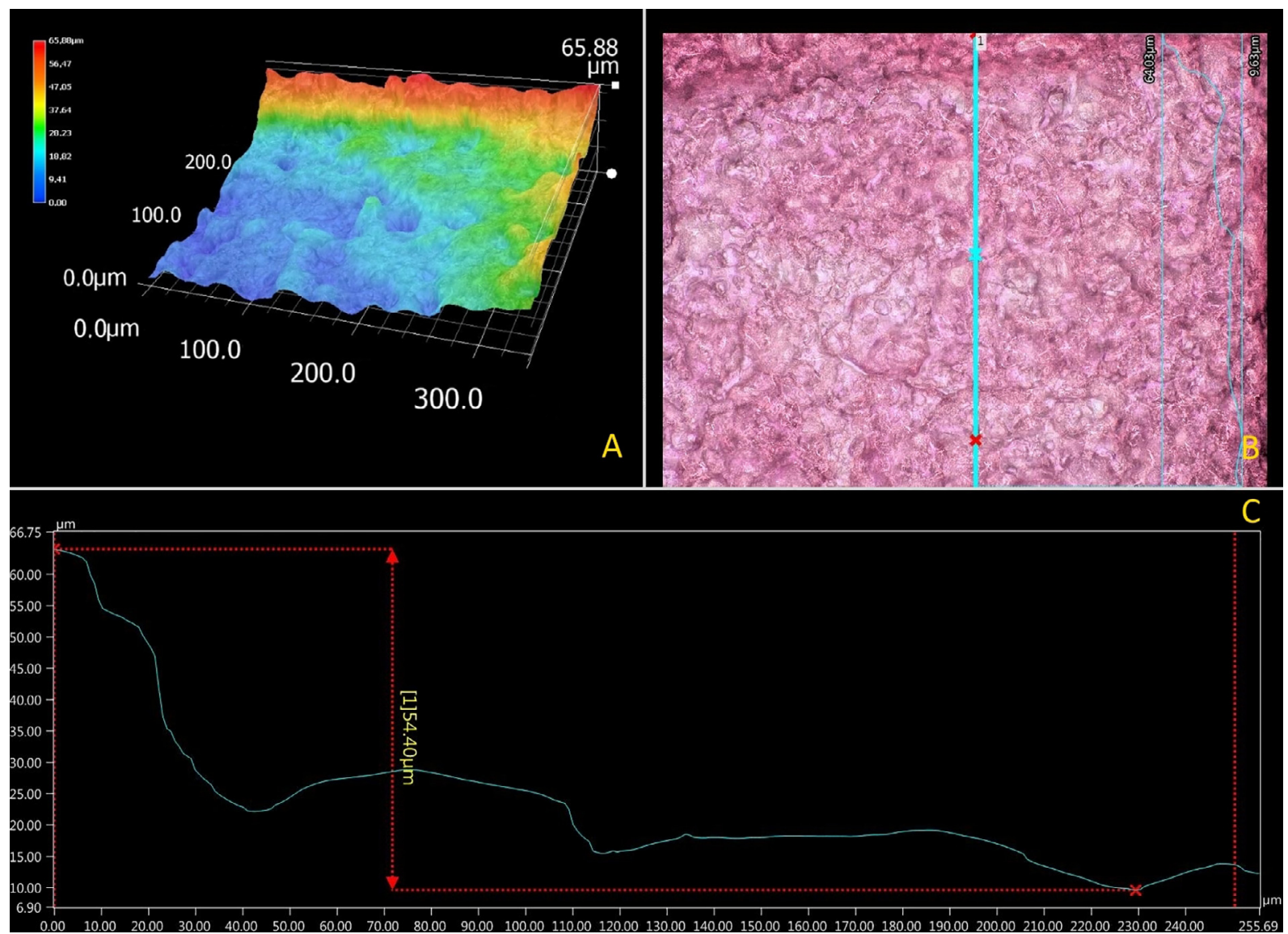

Fig. 6. Surface analysis by 3D microscope of the excimer laser treated region of the Sepifilm NAT Pink coating. A - 3D surface graph, B - top view with original colours of the ablation hole, $\mathrm{C}$ - profile analysis.

Table 2

The compositions and Raman spectroscopic references of conventionally (PW) and naturally (NAT) coloured coatings.

\begin{tabular}{|c|c|c|c|c|}
\hline & & & \multirow{2}{*}{$\begin{array}{l}\text { Literature background Raman activity of } \\
\text { components } \\
\text { (Romann et al., 2010) }\end{array}$} \\
\hline & & \multirow{4}{*}{$\begin{array}{l}\text { HPMC } \\
\text { glycerine } \\
\text { MCC }\end{array}$} & & \\
\hline & & & & \multirow{3}{*}{$\begin{array}{l}\text { (Romann et al., 2010) } \\
\text { (Fechner et al., 2003) }\end{array}$} \\
\hline & & & & \\
\hline & & & & \\
\hline $\begin{array}{l}\text { PW coloured films } \\
\text { HPMC } \\
\text { PEG } \\
\text { Talc } \\
\text { Titanium dioxide } \\
\text { Pigments white: - }\end{array}$ & $\begin{array}{l}\text { Literature background Raman activity of } \\
\text { components } \\
\text { (Romann et al., 2010) } \\
\text { (Romann et al., 2010) } \\
\text { (Szostak and Mazurek, 2002) } \\
\text { (Kato et al., 2010) }\end{array}$ & \multicolumn{2}{|c|}{ Colouring food agents } & \\
\hline \multirow{2}{*}{$\begin{array}{l}\text { red: iron oxide } \\
\text { green: chlorophyll }\end{array}$} & (Li et al., 2012) & \multirow{2}{*}{\multicolumn{2}{|c|}{$\begin{array}{ll} & \text { pink: beetroot } \\
& \text { extract } \\
& \text { green: algae extract }\end{array}$}} & \multirow{2}{*}{$\begin{array}{l}\text { (de Oliveira et al., 2010) } \\
\text { (Weiss et al., 2010) }\end{array}$} \\
\hline & (Koyama et al., 1986) & & & \\
\hline
\end{tabular}

films due to the lack of the disturbing particles.

The result of the treatment by semiconductor laser is black burst signals or the fading of the colour of coatings, which may be seen in Fig. 2A-C or D and E, repectively. To clarify the nature of changes on the treated surface, further investigations were made.

The microscopic pictures of the untreated, excimer laser treated and semiconductor laser treated films may be seen in the first (Fig. 3a, d, g.), second (Fig. 3b, e, h) and third (Fig. 3c, f, i) columns of Fig. 3 respectively. Arrows are pointing at the little white titanium dioxide particles. However, in the square shaped 'print' both black and white particles are seen in Fig. 3b, e.

This phenomenon may be connected to the three existing crystal structures of titanium dioxide, rutile, anatase, and brookite (Hosokawa and Kato, 2011). By the laser treatment of titanium dioxide, apart from ablation, three main events are expected to occur: reduction, phase transition and melting. These can be qualitatively graded according to the respective characteristic temperatures of $500{ }^{\circ} \mathrm{C}, 750{ }^{\circ} \mathrm{C}$, and
$1870{ }^{\circ} \mathrm{C}$. It was reported by Robert et al. that the irradiation of titanium dioxide by $\mathrm{KrF}$ excimer UV pulsed laser at wavelength $248 \mathrm{~nm}$ induced a colour change from white to dark blue, which was the phase transition of anatase to rutile indicating surface reduction (Robert et al., 2003). Furthermore, Kato et al. were studying the mechanism of printing film-coated tablets containing titanium dioxide by using a tripled Nd: YVO4 UV laser printing machine (wavelength of $355 \mathrm{~nm}$ ). They marked clear numbers and letters on the surface of the tablet by turning the colour of the film from white to grey, as a result of the appearance of many black particles in the coloured part of the film. The black particles are formed by the agglomeration of the greyed oxygendefected titanium dioxide by the UV laser irradiation (Kato et al., 2010). It was assumed that in the present case the white and black points in Fig. 3b and e are also associated with the laser irradiated titanium dioxide, since the reactions of titanium dioxide to laser ablation differ significantly from other ingredients of the coating material. Each material has its characteristic ablation threshold. This value is specific 


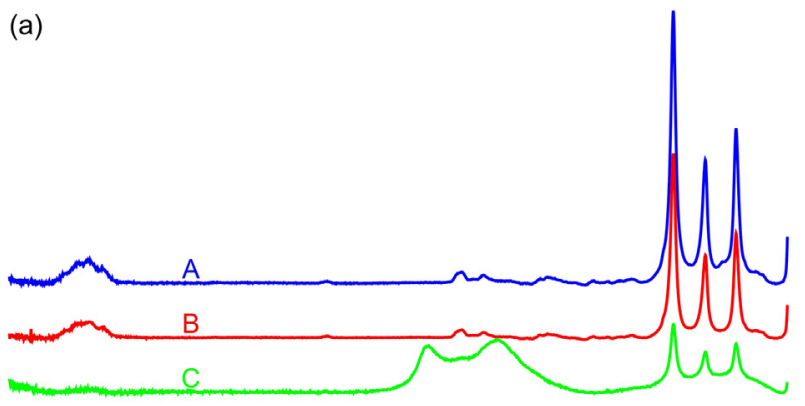

(b)
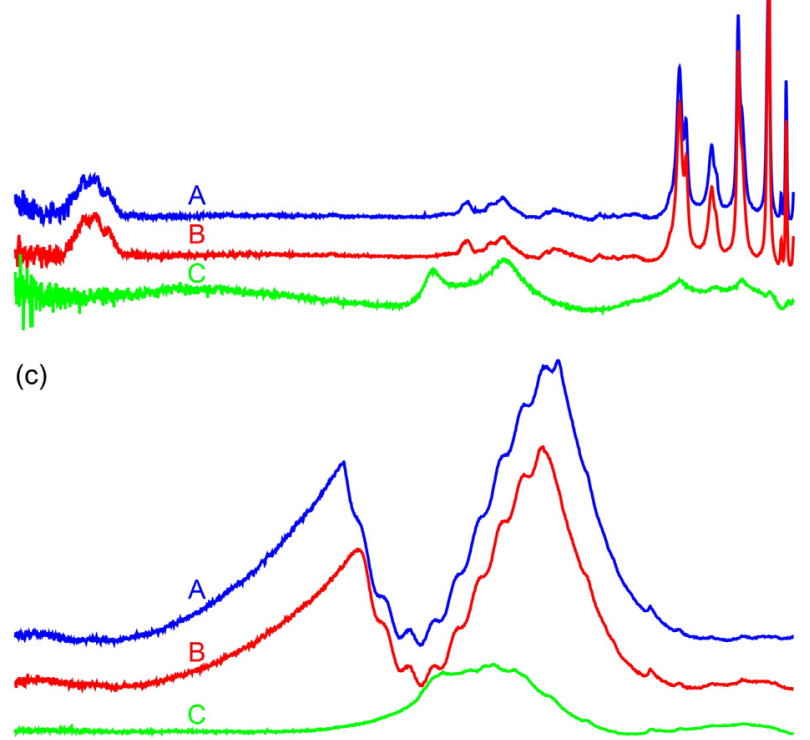

(d)
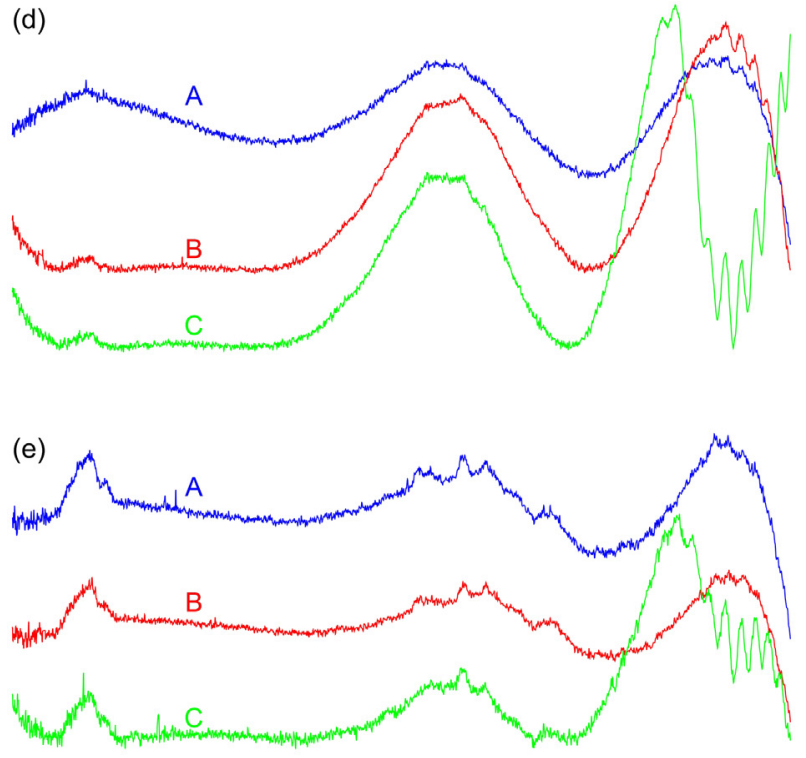

\begin{tabular}{|c|c|c|c|c|c|}
\hline 3000 & 2500 & 2000 & 1500 & 1000 & 500 \\
\hline
\end{tabular}

Fig. 7. Raman spectra of film coatings treated with different lasers (a) Sepifilm PW White, (b) Sepifilm PW Red, (c) Sepifilm PW Green, (d) Sepifilm NAT Pink, (e) Sepifilm NAT Green (A - original, B - excimer laser, C - semiconductor laser). Raman measurements were carried out with a laser power of $12 \mathrm{~mW}$ and in the case of Sepifilm NAT Green $24 \mathrm{~mW}$. to the material, to the type of laser, to the ablation method and to the wavelength and the fluence (Kannatey-Asibu Jr., 2009; Steen and Mazumder, 2010). In the studies of Laude et al., the ablation of talc started at $250 \mathrm{~mJ} / \mathrm{cm}^{2}$ fluence at $248 \mathrm{~nm}$ wavelength, so it is likely that talc has been ablated during the laser treatment (Laude et al., 1997). The ablation of titanium dioxide requires higher fluence than other ingredients of the coating material, and it is likely to require higher fluence than our laser can provide. In the present case the excimer laser was used at $193 \mathrm{~nm}$ wavelength and $444 \mathrm{~mJ} / \mathrm{cm}^{2}$ fluence, whereas literature data about the ablation threshold of titanium dioxide is available only at $248 \mathrm{~nm}$ wavelength and $1.44 \mathrm{~J} / \mathrm{cm}^{2}$ (Van Overschelde et al., 2006) or $910 \mathrm{~mJ} / \mathrm{cm}^{2}$ fluence (Robert et al., 2003). The threshold value in this study was still below the ablation threshold of titanium dioxide and was not enough for its removal, but it was enough for the removal of the rest of the coating. Therefore the presence of these excipients makes precision laser coding by the excimer laser more difficult as particles remain, increasing overall surface roughness and degrading the uniform colour distribution. In the case of the titanium dioxide-free naturally coloured coatings (Fig. $3 \mathrm{~g}$ and $\mathrm{h}$ ), those black and white particles are not visible.

The QR code requires a certain spatial resolution when encoding the desired amount of data. The required (RMS-Root mean squared) surface roughness of the treated region should be less than $10 \mu \mathrm{m}$. In most cases, the untreated tablet surface fulfils that criterion, see Fig. 4.

The previously discussed titanium dioxide enrichment can disturb the $2 \mathrm{D}$ code recognition by increasing surface roughness. The remaining particle size can be about half of the ablation depth, as shown by the results of the excimer laser treated PW Red film as an example (Fig. 5). The designated line where the measurement was taken is passing through the ablation hole (Fig. 5A and B) and the corresponding profile of the ablation hole is shown in Fig. 5C.

The metal oxide and pigment ratio also changed during the ablation procedure. This effect modifies the treated coating colour and, as a result, degrades the 2D code contrast. In contrast, no disturbing white particles are seen in the case of NAT Pink coating (Fig. 6), and the lasered surface is found to be smoother.

According to the literature, it was supposed that the thermal effect of pulsed UV radiation of $193 \mathrm{~nm}$ is negligible, only rapid photochemical reactions take place in the irradiated volume "exploding" the molecules from the surface (photoablation), and there is no time for any heat transfer. This hypothesis was supported by the microscopic pictures where no sign of thermal degradation or modification of the film structure were visible. In contrast, the $404 \mathrm{~nm}$ wavelength diode (semiconductor) laser has a higher wavelength, greater heat effect, and operates with continuous irradiation, where there is enough time for heat transfer, heat propagation and heat accumulation, which can lead to thermal degradation. The signs of melting and burning, causing structural changes and modified porosity of the films are well visible in Figs. 2 and 3 c, f, i.

\subsection{Raman investigations}

As it was discussed above, the 2 types of lasers have a completely different effect on the coatings, which was displayed in the microscopic pictures (Fig. 3). The semiconductor laser seemingly burned or faded out the films. To find out what kind of chemical changes happened, Raman investigations were carried out. Nevertheless, the complex composition of the coatings, - especially the ones that contain natural colourings (e.g., extracts of fruits, vegetables, plants or algae) -, where the exact composition is not known, makes analysis difficult.

The components and the related relevant literature for Raman spectroscopic examinations are listed in Table 2.

The fingerprint region of Sepifilm is $1800 \mathrm{~cm}^{-1}-500 \mathrm{~cm}^{-1}$. The spectra of raw free films and films treated by different lasers are summarized in Fig. 7. In all cases, the spectra of the films treated by the semiconductor laser changed the fingerprint region of Sepifilm, while 
Table 3

Decomposition behavior of the raw polymer film and the film treated by laser.

\begin{tabular}{|c|c|c|c|}
\hline TG data & Sepifilm ${ }^{\oplus}$ NAT. P. film & Sepifilm ${ }^{\circledast}$ NAT. P. film treated with excimer laser & Sepifilm ${ }^{\circledast}$ NAT. P. film treated with semiconductor laser \\
\hline \multicolumn{4}{|l|}{ First step } \\
\hline Thermal range $\left({ }^{\circ} \mathrm{C}\right)$ & $25-120$ & $25-120$ & $25-120$ \\
\hline Mass loss (\%) & 2.85 & 4.05 & 4.91 \\
\hline \multicolumn{4}{|l|}{ Second step } \\
\hline Thermal range $\left({ }^{\circ} \mathrm{C}\right)$ & $290-430$ & $290-430$ & $290-430$ \\
\hline Mass loss (\%) & 58.26 & 59.98 & 68.94 \\
\hline TG data & Sepifilm ${ }^{\oplus}$ PW R film & Sepifilm ${ }^{\circledast}$ PW R film treated with excimer laser & Sepifilm ${ }^{\circledast}$ PW R film treated with semiconductor laser \\
\hline \multicolumn{4}{|r|}{ 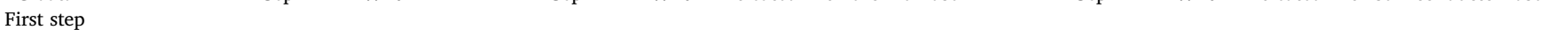 } \\
\hline Thermal range $\left({ }^{\circ} \mathrm{C}\right)$ & $25-120$ & $25-120$ & $25-120$ \\
\hline Mass loss (\%) & 1.07 & 1.15 & 1.80 \\
\hline \multicolumn{4}{|l|}{ Second step } \\
\hline Thermal range $\left({ }^{\circ} \mathrm{C}\right)$ & $290-440$ & $290-440$ & $290-440$ \\
\hline Mass loss $(\%)$ & 51.88 & 52.11 & 55.12 \\
\hline TG data & Sepifilm ${ }^{\circledast}$ PW W film & Sepifil ${ }^{\oplus}$ PW W film treated with excimer laser & Sepifilm ${ }^{\circledast}$ PW W film treated with semiconductor laser \\
\hline Thermal range $\left({ }^{\circ} \mathrm{C}\right)$ & $25-500$ & $25-500$ & $25-500$ \\
\hline Mass loss (\%) & 56.06 & 54.80 & 65.63 \\
\hline
\end{tabular}

the excimer laser did not cause considerable alteration in the coatings.

Firstly, it should be emphasized that the polymer films containing the extract of colouring foodstuffs, Sepifilm PW Green, NAT Pink and NAT Green (Table 2) exhibited severe fluorescence during the measurement (Fig. 7c-e). This effect could not be corrected by photobleaching, and it has made the analysis difficult or impossible. In the case of PW Green, fluorescence disappeared after marking it by the semiconductor laser, presumably because of a change in the structure of chlorophyll, which resulted in the change of the colour of the coating (Fig. 2).

Among the listed components, titanium dioxide is one of the most important that had an effect on the lasering results, which has already been discussed above. In the corresponding articles, the peaks of the Raman spectra of titanium dioxide may be found at 396, 516 and $638 \mathrm{~cm}^{-1}$, which characteristic peaks were found in the Raman spectra of Seppic PW films (Fig. 7a-c). These peaks exhibited a minor decrease in films treated by the excimer laser, and a more considerable decrease in intensity when they were lasered by the semiconductor laser, in the same way as Kato et al. have reported (Kato et al., 2010). In the same spectra, considerable fluorescence was detectable in the region of $1700 \mathrm{~cm}^{-1}$ to $1200 \mathrm{~cm}^{-1}$ in the case of the semiconductor laser treated films, which is likely due to the product degradation that had occurred during the laser treatment.

\subsection{Thermal gravimetric analysis (TGA)}

To reveal the effect of the assumed chemical changes on the structure of the films, TGA measurements were performed. The main characteristics of the samples derived from TG curves as corresponding mass loss values (Table 3) were used to define the thermal behaviour and combustion characteristics of films. It is seen that mass loss in Sepifilm NAT Pink and Sepifilm PW Red coating comes in two stages. The first mass loss occurred between 25 and $120^{\circ} \mathrm{C}$ with both coatings, the second stage between 290 and $430^{\circ} \mathrm{C}$ in the case of NAT Pink film, and between 290 and $440{ }^{\circ} \mathrm{C}$ in the case of PW Red. The mass loss of Sepifilm PW White film was observed between 25 and $500{ }^{\circ} \mathrm{C}$.

The TG curves revealed that the decomposition occurred sooner in Sepifilm NAT Pink, PW White, and PW Red coatings if they were marked by a semiconductor laser, as it may be seen in Fig. 8. These results correlate with the results of our previous research (Ludasi et al., 2018). It may be seen from the microscopic mosaic picture of the preand post-lasered films that in contrast with the untreated intact films (Fig. 3a, d, g), the semiconductor laser treated films (Fig. 3c, f, i) exhibit damaged structures. Holes may be seen, especially on the Sepifilm PW White film (Fig. 3f) surrounded by a wide range of melted area. A damaged structure and larger pores appeared, suggesting that water can escape more easily from the internal parts of the material as a result of the heat effect. Therefore, it can be concluded that the weight loss seen in the first step of the TG curve may show the water loss of the films (Fig. 8a and c). The visual signals of the damage (Fig. 3c, f, i) and the corresponding TG curves of semiconductor laser treated films, - where all of these curves reveal that decomposition occurred sooner -, all indicate that the decomposition process had already started during the laser marking process. In contrast, in the micrographs of the excimer laser treated films (Fig. 3b, e, h) it is seen that the ablated surface of the sample exhibits no considerable destruction, the structure of the film is relatively intact. The TG curves of the excimer laser marked films run together with the curves of the original, untreated film. Overall, the earlier the mass loss of TG curves began, the more damaged the surface of semiconductor laser-coded coatings was, and the lack of these signs on the excimer laser treated ones indicates well the different effects of different lasers on the films.

\section{Conclusion}

In this study, the behaviour of conventional coating compared to ones containing natural colourings was examined during marking with different lasers. The results demonstrated that the excimer laser could be the right instrument for marking functional coatings, since it caused no structural damage in the treated films. However, the laser treatment of the naturally coloured material can be performed more accurately, with greater precision due to the lack of remaining particles disturbing the reading of the ablated codes. It can also be concluded that laser ablation differentiates the ingredients of the conventional coating as the white titanium dioxide particles stay in place and they change the overall surface colour, which can affect drug identification. Marking pills by excimer laser could be a promising solution for pharmaceutical companies that would like to have additional protection against drug counterfeiters or to mark personalized medicines. It is also an important conclusion that, despite the resulting chemical modifications, semiconductor lasers may be useful and cheaper alternative for tablet coding if marking is performed on non-functional coating which is thick enough to avoid heat transfer into the tablet core, and if no harmful byproduct is formed as a result of the heat. These technologies would not be mandatory, but the option is there to use them as they could have several useful features, too.

\section{Declaration of Competing Interest}

The authors declare that they have no known competing financial interests or personal relationships that could have appeared to influence the work reported in this paper. 

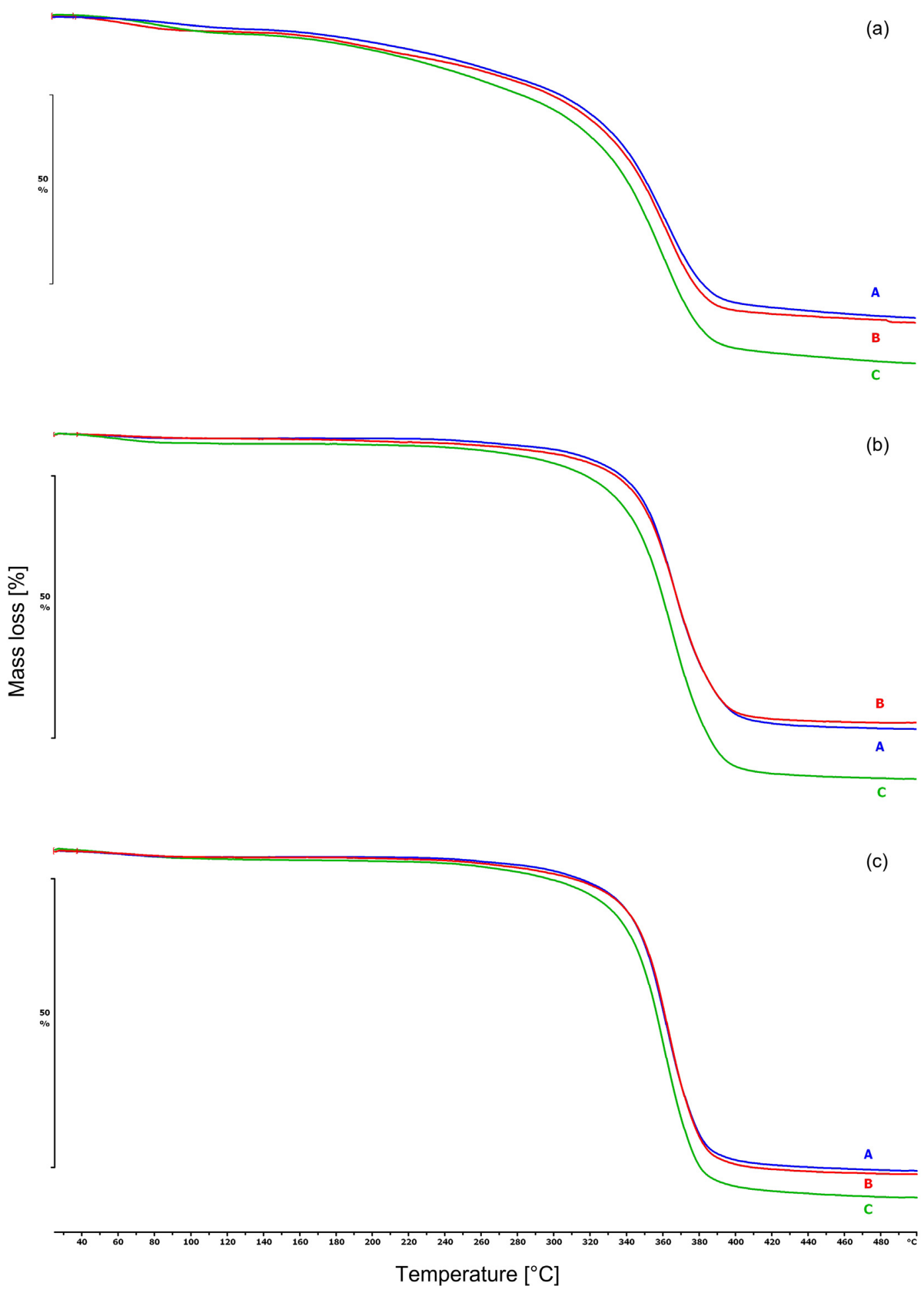

Fig. 8. TG curves of Sepifilm (a) NAT Pink, (b) PW White, (c) PW Red film treated with different lasers (A - original, B - excimer laser, C - semiconductor laser).

\section{Acknowledgement}

I would like to thank Seppic S.A. for supplying the polymers, KEYENCE Corporation for providing the digital microscope with knowledgeable technical assistance, and Imre Gódány, who helped with the measurements.

This research was supported by the EU-funded Hungarian grant EFOP-3.6.1-16-2016-00008

\section{References}

Bichell, R.E., 2017. Fake drugs are a major global. Problem, WHO Reports.

Daehwan, J., Dongjo, K., Jooho, M., 2009. Influence of fluid physical properties on ink-jet printability. Langmuir 25, 2629-2635.

Davison, M., 2011. Pharmaceutical Anti-Counterfeiting Combating the Real Danger from Fake Drugs. John Wiley \& Sons Inc., Publication, pp. 103-140.

de Oliveira, V.E., Castro, H.V., Edwards, H.G.M., de Oliveiraa, L.F.C., 2010. Carotenes and carotenoids in natural biological samples: A Raman spectroscopic analysis. J. Raman Spectrosc. 41, 642-650. https://doi.org/10.1002/jrs.2493.

Kannatey-Asibu Jr., E., 2009. Principles of Laser Materials Processing. John Wiley\&Sons. Edinger, M., Bar-Shalom, D., Sandler, N., Rantanen, J., Genina, N., 2018. QR encoded 
smart oral dosage forms by inkjet printing. Int. J. Pharm. 536, 138-145. https://doi. org/10.1016/j.ijpharm.2017.11.052.

European Comission, 2016. REGULATIONS COMMISSION DELEGATED REGULATION (EU) 2016/161 of 2 October 2015 supplementing Directive 2001/83/EC of the European Parliament and of the Council by laying down detailed rules for the safety features appearing on the packaging medicinal product. Off. J. Eur. Union L 32/1L32/27.

European Commission. 2003. Commission Communication on parallel imports of proprietary medicinal products for which marketing authorisations have already been granted EN.

European Commission Staff Working Document, 2015. COMMISSION DELEGATED REGULATION (EU) No/ supplementing Directive 2001/83/EC of the European Parliament and of the Council by Laying Down Detailed Rules for the Safety Features Appearing on the Packaging of Medicinal Product for Human Use. European Commision.

European Medicines Agency. 2019. Human Regulatory, Frequently asked questions about parallel distribution. < https://www.ema.europa.eu/en/human-regulatory/postauthorisation/parallel-distribution/frequently-asked-questions-about-paralleldistribution $>$ (accessed 3.29.19).

FDA. 2014. Drug Supply Chain Security. < http://www.fda.gov/Drugs/DrugSafety/ DrugIntegrityandSupplyChainSecurity/DrugSupplyChainSecurityAct/ > (accessed 3. 4.19).

Fechner, P.M., Wartewig, S., Füting, M., Heilmann, A., Neubert, R.H.H., Kleinebudde, P., 2003. Properties of microcrystalline cellulose and powder cellulose after extrusion/ spheronization as studied by fourier transform raman spectroscopy and environmental scanning electron microscopy. AAPS J. 5, 1-13.

Fei, J., Liu, R., 2016. Drug-laden 3D biodegradable label using QR code for anti-counterfeiting of drugs. Mater. Sci. Eng. C 63, 657-662. https://doi.org/10.1016/j.msec. 2016.03.004.

Gallagher, J.C., Colaizzi, J.L., 2000. Issues in internet pharmacy practice. Ann. Pharmacother. 34, 1483-1485. https://doi.org/10.1345/aph.10130.

Ghinea, G., Asgari, S., Moradi, A., Serif, T., 2006. A Jini-based solution for electronic prescriptions. IEEE Trans. Inf. Technol. Biomed. 10, 794-802. https://doi.org/10. 1109/TITB.2006.879586.

Hosokawa, A., Kato, Y., 2011. Factors affecting color strength of printing on film-coated tablets by UV laser irradiation: $\mathrm{TiO}_{2}$ particle size, crystal structure, or concentration in the film, and the irradiated UV laser power. Drug Dev. Ind. Pharm. 37, 901-906. https://doi.org/10.3109/03639045.2010.548816.

Langhauser, Karen, 2013. If You Drop QR Codes, Do They Bounce Back? Phamaceutical Manuf.

Kato, Y., Nakashima, Y., Shino, N., Sasaki, K., Hosokawa, A., Ishihara, H., 2010. Studies on the mechanism of printing film-coated tablets containing titanium dioxide in the film by using UV laser irradiation. Drug Dev. Ind. Pharm. 36, 405-412. https://doi. org $/ 10.3109 / 03639040903213725$.

Koyama, Y., Umemoto, Y., Akamatsu, A., Uehara, K., Tanaka, M., 1986. Raman spectra of chlorophyll forms. J. Mol. Struct. 146, 273-287. https://doi.org/10.1016/00222860(86)80299-X.

Laude, L.D., Soudant, S., Beauvois, S., Renaut, D., Jadin, A., 1997. Laser ablation of charged polymers. Nucl. Instrum. Methods Phys. Res. Sect. B Beam Interact. Mater. Atoms 131, 211-218. https://doi.org/10.1016/S0168-583X(97)00137-7.

Li, Y.S., Church, J.S., Woodhead, A.L., 2012. Infrared and Raman spectroscopic studies on iron oxide magnetic nano-particles and their surface modifications. J. Magn. Magn. Mater. 324, 1543-1550. https://doi.org/10.1016/j.jmmm.2011.11.065.

Ludasi, K., Sovány, T., Laczkovich, O., Hopp, B., Smausz, T., Regdon, G., 2018. Unique laser coding technology to fight falsified medicines. Eur. J. Pharm. Sci. 123, 1-9. https://doi.org/10.1016/j.ejps.2018.07.023.

Mackey, T.K., Nayyar, G., 2017. A review of existing and emerging digital technologies to combat the global trade in fake medicines. Expert Opin. Drug Saf. 16, 587-602. https://doi.org/10.1080/14740338.2017.1313227.

Mira, J.J., Guilabert, M., Carrillo, I., Fernández, C., Vicente, M.A., Orozco-Beltrán, D., GilGuillen, V.F., 2015. Use of QR and EAN-13 codes by older patients taking multiple medications for a safer use of medication. Int. J. Med. Inform. 84, 406-412. https:// doi.org/10.1016/j.ijmedinf.2015.02.001.

Nayyar, G.M.L., Breman, J.G., Mackey, T.K., Clark, J.P., Hajjou, M., Littrell, M., Herrington, J.E., 2019. Falsified and substandard drugs: stopping the pandemic. Am. J. Trop. Med. Hyg. 00, 1-8. https://doi.org/10.4269/ajtmh.18-0981.

Nogaja, J.S., 2013. Micro-tag: a novel technique of security in pharmaceuticals. Int. J. Pharm. Sci. Res. 4, 29-33.

Renschler, J.P., Walters, K.M., Newton, P.N., Laxminarayan, R., 2015. Estimated underfive deaths associated with poor-quality antimalarials in sub-saharan Africa. Am. J.
Trop. Med. Hyg. 92, 119-126. https://doi.org/10.4269/ajtmh.14-0725.

Robert, T.D., Laude, L.D., Geskin, V.M., Lazzaroni, R., Gouttebaron, R., 2003. MicroRaman spectroscopy study of surface transformations induced by excimer laser irradiation of $\mathrm{TiO}_{2}$. Thin Solid Films 440, 268-277. https://doi.org/10.1016/S00406090(03)00819-8.

Romann, J., Valmalette, J.C., Chevallier, V., Merlen, A., 2010. Surface interactions between molecules and nanocrystals in copper oxalate nanostructures. J. Phys. Chem. C 114, 10677-10682. https://doi.org/10.1021/jp9082344.

Said, M.M., Gibbons, S., Moffat, A.C., Zloh, M., 2011. Near-infrared spectroscopy (NIRS) and chemometric analysis of Malaysian and UK paracetamol tablets: A spectral database study. Int. J. Pharm. 415, 102-109. https://doi.org/10.1016/j.ijpharm.2011. 05.057.

Siva, N., 2010. Tackling the booming trade in counterfeit drugs. Lancet 376, 1725-1726 https://doi.org/10.1016/S0140-6736(10)62118-6.

Szostak, R., Mazurek, S., 2002. Quantitative determination of acetylsalicylic acid and acetaminophen in tablets by FT-Raman spectroscopy. Analyst 127, 144-148. https:// doi.org/10.1039/b108240j.

The European Parlament and the Council of the European Union, 2011. Directive 2011/ $62 / \mathrm{EU}$ of the European parliament and of the council of 8 June 2011. Off. J. Eur. Union L 174 (74), 74-87.

Trenfield, S.J., Xian Tan, H., Awad, A., Buanz, A., Gaisford, S., Basit, A.W., Goyanes, A., 2019. Track-and-trace: Novel anti-counterfeit measures for 3D printed personalized drug products using smart material inks. Int. J. Pharm. 567. https://doi.org/10. 1016/j.ijpharm.2019.06.034.

TruTag Technologies. 2019. Brand Protection for Pharmaceutical + Nutraceutical. $<$ https://trutags.com/pharmaceutical-nutraceutical/ > .

UNICRI. 2012. Counterfeit Medicine and organised crime. < http://www.unicri.it/ topics/counterfeiting/medicines/report/Ctf_medicines_and_oc_advance_ unedited2013.pdf $>$ (accessed 5.8.19).

Ur Rehman, S., Ur Rasool, R., Ayub, M.S., Ullah, S., Kamal, A., Rajpoot, Q.M., Anwar, Z., 2011. Reliable identification of counterfeit medicine using camera equipped mobile phones. 8th Int. Conf High-Capacity Opt. Networks Emerg. Technol. HONET 2011, 273-279. https://doi.org/10.1002/pi.4602.

Vakili, H., Kolakovic, R., Genina, N., Marmion, M., Salo, H., Ihalainen, P., Peltonen, J., Sandler, N., 2015. Hyperspectral imaging in quality control of inkjet printed personalised dosage forms. Int. J. Pharm. 483, 244-249. https://doi.org/10.1016/j. ijpharm.2014.12.034.

Van Overschelde, O., Dinu, S., Guisbiers, G., Monteverde, F., Nouvellon, C., Wautelet, M., 2006. Excimer laser ablation of thin titanium oxide films on glass. Appl. Surf. Sci. 252, 4722-4727. https://doi.org/10.1016/j.apsusc.2005.07.147.

Vida, R.G., Fittler, A., Mikulka, I., Ábrahám, E., Sándor, V., Kilár, F., Botz, L., 2017. Availability and quality of illegitimate somatropin products obtained from the Internet. Int. J. Clin. Pharm. 39, 78-87. https://doi.org/10.1007/s11096-016 0398-y.

Weiss, T.L., Chun, H.J., Okada, S., Vitha, S., Holzenburg, A., Laane, J., Devarenne, T.P., 2010. Raman spectroscopy analysis of botryococcene hydrocarbons from the green microalga botryococcus braunii. J. Biol. Chem. 285, 32458-32466. https://doi.org/ 10.1074/jbc.M110.157230.

WHO, 2017a. Seventieth World Health Assembly Update, 29 May 2017, Who.

WHO, 2017b. WHO Global Surveillance and. Monitoring System.

WHO, 2017c. A study on the public health and socioeconomic impact of substandard and falsified medical products.

WHO. 2017d. 1 in 10 Medical Products in Developing Countries Is Substandard or Falsified. Who. < http://www.who.int/mediacentre/news/releases/2017/ substandard-falsified-products/en/ > (accessed 11.7.18).

WHO IMPACT. 2006. Counterfeit Medicines: an update on estimates 15 November 2006.

Wilczyński, S., 2015. The use of dynamic thermal analysis to distinguish between genuine and counterfeit drugs. Int. J. Pharm. 490, 16-21. https://doi.org/10.1016/j.ijpharm. 2015.04.077.

Steen, W.M. and Mazumder, J. 2010. Laser Material Processing, 4th ed. Springer.

World Health Assembly, 2017. WHO Member State Mechanism on Substandard/ Spurious/Falsely-Labelled/Falsified/Counterfeit (SSFFC) Medical Products. Seventieth World Heal. Assem. A70 (23), 33-36.

You, M., Lin, M., Wang, S., Wang, X., Zhang, G., Hong, Y., Dong, Y., Jin, G., Xu, F., 2016. Three-dimensional quick response code based on inkjet printing of upconversion fluorescent nanoparticles for drug anti-counterfeiting. Nanoscale 8, 10096-10104. https://doi.org/10.1039/c6nr01353h.

Zanjal, S.V., Talmale, G.R., 2016. Medicine Reminder and Monitoring System for Secure Health Using IOT. Phys. Procedia. https://doi.org/10.1016/j.procs.2016.02.090. 